\title{
An Analytical Model for the Identification of the Threshold of Stress Intensity Factor Range for Crack Growth
}

\author{
Marzio Grasso, ${ }^{1}$ Antonio De Iorio, ${ }^{2}$ Yigeng $\mathrm{Xu},{ }^{3}$ George Haritos, \\ M. Mohin, ${ }^{1}$ and Yong K. Chen ${ }^{1}$ \\ ${ }^{1}$ School of Engineering and Technology, University of Hertfordshire, College Lane Campus, Hatfield AL10 9AB, UK \\ ${ }^{2}$ Department of Industrial Engineering, University of Naples Federico II, 80125 Naples, Italy \\ ${ }^{3}$ School of Aerospace, Transport and Manufacturing, Cranfield University, Cranfield, Bedfordshire MK43 OAL, UK \\ Correspondence should be addressed to Marzio Grasso; m.grasso@herts.ac.uk
}

Received 22 July 2016; Revised 30 September 2016; Accepted 18 October 2016; Published 18 January 2017

Academic Editor: Ming-Xing Zhang

Copyright (C) 2017 Marzio Grasso et al. This is an open access article distributed under the Creative Commons Attribution License, which permits unrestricted use, distribution, and reproduction in any medium, provided the original work is properly cited.

\begin{abstract}
The value of the stress intensity factor (SIF) range threshold $\left(\Delta K_{\text {th }}\right)$ for fatigue crack growth (FCG) depends highly on its experimental identification. The identification and application of $\Delta K_{\text {th }}$ are not well established as its determination depends on various factors including experimental, numerical, or analytical techniques used. A new analytical model which can fit the raw FCG experimental data is proposed. The analytical model proposed is suitable to fit with high accuracy the experimental data and is capable of estimating the threshold SIF range. The comparison between the threshold SIF range identified with the model proposed and those found in the literature is also discussed. $\Delta K_{\text {th }}$ identified is found to be quite accurate and consistent when compared to the literature with a maximum deviation of 5.61\%. The accuracy with which the analytical model is able to fit the raw data is also briefly discussed.
\end{abstract}

\section{Introduction}

FCG threshold $\left(\Delta K_{\mathrm{th}}\right)$ is one of the key parameters representing material resistance to fatigue crack growth (FCG). Newman Jr. referred to the Federal Aviation Administration (FAA) by mentioning that, traditionally, threshold is used as a limit for the damage tolerance design (DTD) [1, 2]. $\Delta K_{\text {th }}$ has been used over the past 40 years in numerous FCG models available in the literature [3-18]. However, the identification of $\Delta K_{\mathrm{th}}$ and its application in structures residual life prediction are not quite straightforward, as it varies both qualitatively and quantitatively due to various experimental, numerical, and analytical methods and corresponding assumptions used [19]. Whilst FCG curves of physically small crack and microstructurally small crack have different shapes [20], FCG can be represented by the sigmoidal curve of $\log (\Delta K)-\log (d a / d N)$ for long cracks as shown in Figure 1 [21]. This figure depicts three regions: Region I, Region II, and Region III. Region I is taken as either very slow crack growth region or near-threshold region since the SIF range of the sigmoidal curve in this region asymptotically approaches $\Delta K_{\mathrm{th}}$. The Paris Law [22] is normally applicable to the crack growth in Region 2 . There are several models available to represent the whole sigmoidal curve covering all three regions. One of the models developed by NASA and represented by Forman and Mettu $[10,21]$ is given in

$$
\frac{d a}{d N}=C \Delta K^{m} \frac{\left(1-\Delta K_{\mathrm{th}} / \Delta K\right)^{p}}{\left(1-K_{\max } / K_{C}\right)^{q}},
$$

where $C, m, p$, and $q$ are material constants, SIF range $(\Delta K)=$ maximum $\operatorname{SIF}\left(K_{\max }\right)-\operatorname{minimum} \operatorname{SIF}\left(K_{\min }\right), K_{C}=\operatorname{SIF}$ at fracture, and $\Delta K_{\text {th }}=$ SIF range at threshold.

Ideally, $\Delta K_{\mathrm{th}}$ is the value of SIF range $(\Delta K)$ below which fatigue crack will not grow [21]. However, it has been shown [23] that cracks propagate even below the largecrack threshold measured by ASTM test procedure $[1,24]$. Therefore, $\Delta K_{\text {th }}$ is also defined to be a value of $\Delta K$ at which crack growth rate $(d a / d N)$ is below $10^{-10} \mathrm{~m} /$ cycle $[1,25]$. It 


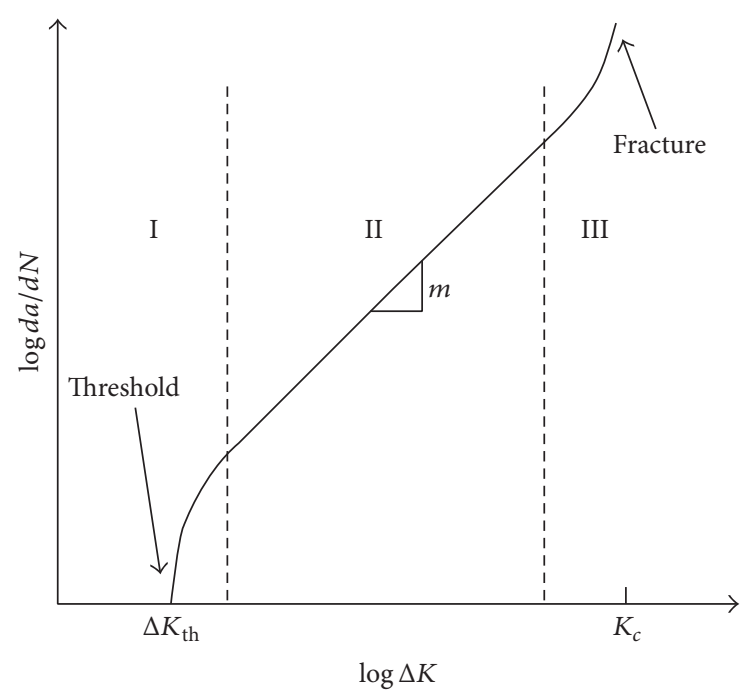

FIGURE 1: Typical sigmoidal curve of fatigue crack growth [21].

is sometimes experimentally determined by extrapolation to $d a / d N=0$ from lower tail of the sigmoidal curve of raw data when linear-linear scale is considered [19]. Residual life of a structure can highly be influenced by a variation of $\Delta K_{\mathrm{th}}$. As reported by Molent and Jones [18] and mentioned by Zerbst and Vormwald $[19,26]$, a variation in the threshold SIF range of $1 \mathrm{MPa} \mathrm{m}{ }^{0.5}$ can result in a variation of about $18 \%$ in the residual life. This also provides important insights into how relevant and reasonable it is to determine $\Delta K_{\text {th }}$ accurately in DTD approach.

There are several experimental methods available to determine $\Delta K_{\mathrm{th}}$. These are

(i) load reduction method (LRM);

(ii) $K_{\max }$ constant method;

(iii) far-field cyclic compression method [19].

Load reduction method is standardised by ASTM 647 [24] or ISO 12108 [27]. The load is reduced stepwise to find $\Delta K_{\text {th }}$ in a precracked specimen at a constant $R$. In $K_{\max }$ method, the same stepwise reduction of the load range is followed but at the same time $R$ is increased by maintaining the same maximum SIF value. The far-field compression method can be divided into three submethods:

(i) Compression precracking constant amplitude (CPCA)

(ii) Compression precracking load reduction (CPLR)

(iii) Cyclic $R$ curve method

A detailed review of all these methods is given by Zerbst et al. in [19].

The $\Delta K_{\text {th }}$ values obtained with the mentioned methods can however be quite different due to the different mechanisms involved. These mechanisms are related to the plasticity induced ahead of the crack tip as well as the conditions of the fracture surfaces. Comparatively lower threshold values have been found using the far-field cyclic compression method rather than using the load reduction method [1, 2, 28-30]. This is due to the fact that the far-field cyclic compression method is affected by the compressive yielding at the crackstarter notch and more "steady-state" constant amplitude data in near-threshold regime is achieved with this method [29]. Crack surface roughness and grain size near the crack tip also influence the overall $\Delta K_{\text {th }}[1,31]$. In general, greater size of grains promotes roughness induced crack closure (RICC) and oxide-induced crack closure (OICC) is enhanced simultaneously [32]. The above phenomena increase the $\Delta K_{\text {th }}$ values when measured. Consequently, in LR method, crack faces can produce rough-surface or fretting debris which contributes to the early crack closure and higher $\Delta K_{\mathrm{th}} . \Delta K_{\mathrm{th}}$ varies with mechanically short and long cracks. Linear-elastic fracture mechanics (LEFM) is normally only applicable in long cracks under small scale yielding conditions. Newman [33] has recently referred that $\Delta K_{\text {th }}$ is not valid in gigacycle fatigue region for short cracks as there is no continuous crack propagation below $(d a / d N)=10^{-7} \mathrm{~mm} /$ cycle, which is smaller than one lattice spacing per cycle [19]. In general terms, it is possible to find in the literature [34] two different $\Delta K_{\text {th }}$ levels: microstructural threshold for short crack and mechanical threshold for long crack [35]. The difference is related to the advancement of a short crack at microstructural level and stable propagation of a longer crack having a plastic zone which covers several grains. Moreover, at low SIF, the FCG rate is more sensitive to microstructure, load ratio, and environment for long cracks [20]. However, there is a minimum value independent of $R$, which can be considered as material property and for this reason is called intrinsic threshold, also known as effective or true threshold [34]. Moreover, intrinsic threshold can be increased by the increase of stiffness and strength of the material $[19,36,37]$. Another important effect is related to the specimen geometry. $\Delta K_{\text {th }}$ seems to be lower in $\mathrm{M}(T)$ specimen than in $\mathrm{C}(T)$ specimen for the same $\Delta K$ condition $[38,39]$. The justification should be related to the geometrical constraint or $T$-stress, which is found to be lower in $\mathrm{M}(T)$ specimen ( $T$-stress $<0$ ), compared to $\mathrm{C}(T)$ specimen ( $T$-stress $>0$ ) even though $T$-stress has different effects (e.g., PICC) which might contradict this observation. However, the lowest stress triaxiality at the crack tip associated with the $\mathrm{M}(T)$ specimen produces a much bigger plastic zone near the crack tip than the geometry with a high level of the constraint like the $C(T)$ specimen [40].

Considering the fact that it is difficult to separate the extrinsic threshold from the intrinsic threshold using the crack growth data [34], the focus of this paper is to develop a model which can reliably predict the overall threshold of the material under certain loading conditions. In particular, since the model makes use of the raw data generated with a given specimen geometry under certain loading conditions, the analysis of the raw data includes both the load ratio and the $T$-stress effects. The value identified with the model can be an intrinsic or an extrinsic value depending on the testing conditions at which the data has been acquired.

As discussed above, the $\Delta K_{\text {th }}$ value usually decreases with the increase of $R$ [41]. Two types of $R$-dependency have been reported in the literature [34]. In some cases, $\Delta K_{\text {th }}$ decreases up to a critical value of $R$ and then it becomes constant 
beyond that value [19]. In other cases, $\Delta K_{\text {th }}$ continues to decrease beyond the critical value of $R$ [42]. Klesnil and Lukáš [3] used the following equation to identify $\Delta K_{\text {th }}$ in a steel alloy:

$$
\Delta K_{\mathrm{th}}=\Delta K_{\mathrm{th} 0}(1-R)^{\gamma},
$$

where $R$ is the stress ratio, $\Delta K_{\text {th } 0}$ is the fatigue threshold value at $R=0$, and $\gamma$ is the material constant. However, other approaches [43] have been adopted like the one reported by Kwofie in which an equivalent stress approach based on $R$ ratio is used to identify fatigue threshold value. In general, it has been recognised that crack closure is found to be the controlling factor in this case [18, 44]. For this reason, a different parameter has been introduced $\Delta K_{\mathrm{thr}}$, which is a FCG threshold value that depends on $R$ and the crack length value. In the literature, the scatter in fatigue life was explained by the variation of $\Delta K_{\mathrm{thr}}$ values [18]. Further methods to experimentally identify the threshold condition have been recently developed using plain fretting crack arrest analysis. The dispersion between long crack $\Delta K_{\text {th }}$ fretting estimations and conventional fatigue data was found to be less than $10 \%$ [45].

Due to the high variability of the $\Delta K_{\text {th }}$ values, the determination of the FCG threshold cannot be certain [19]. Although several models have been proposed to experimentally identify the threshold values, all of them suffer from issues related to the plasticity induced closure effects. For this reason, threshold values reported in the literature for the same material can vary in a wide range due to the different procedures that were followed. The aim of this paper is to present a new procedure to identify FCG threshold value for long crack which can overcome the problems related to the experimental procedures reported in the literature. The analytical model proposed here makes use of FCG data obtained from $K$-increasing tests, which are used to derive the FCG properties of the material under the long crack condition, allowing us to identify under the same testing conditions the three regions of the entire sigmoidal curve, from the threshold condition up to the final value of the crack length.

\section{Test Results for Model Development}

Propagation models built on results obtained from a limited number of tests not only have a validity range closely linked to the particular experimentation carried out, but also are not suitable to fit all crack growth data with the same accuracy for the whole field of number of cycles for each test [46]. In order to overcome these drawbacks, several FCG datasets obtained with different materials, loading conditions, and types of specimens have been collected from the literature. These datasets have been used to verify the suitability of the model in fitting the experimental raw data as well as identify the $\Delta K_{\text {th }}$ values of the materials at the corresponding $R$ values. A short description of the datasets collected from the literature is as follows.

2.1. Ghonem and Dore [47]. Ghonem and Dore [47] carried out tests at room temperature using $\mathrm{M}(T)$ specimens made
TABLE 1: Loading conditions related to Ghonem and Dore tests.

\begin{tabular}{lcccc}
\hline & $P_{\max }(\mathrm{kN})$ & $P_{\min }(\mathrm{kN})$ & $\Delta P(\mathrm{kN})$ & $R$ \\
\hline Test I & 22.79 & 13.68 & 9.11 & 0.6 \\
Test II & 22.25 & 11.13 & 11.12 & 0.5 \\
Test III & 15.19 & 6.08 & 9.11 & 0.4 \\
\hline
\end{tabular}

TABLE 2: Loading conditions related to $\mathrm{Wu}$ and $\mathrm{Ni}$ tests.

\begin{tabular}{lcccc}
\hline & $P_{\max }(\mathrm{kN})$ & $P_{\min }(\mathrm{kN})$ & $\Delta P(\mathrm{kN})$ & $R$ \\
\hline CA1 & 4.5 & 0.9 & 3.6 & 0.2 \\
$\mathrm{CA2}$ & 6.118 & 3.882 & 2.236 & 0.63 \\
\hline
\end{tabular}

of aluminium alloy 7075-T6 having a thickness of $3.175 \mathrm{~mm}$. The crack direction was perpendicular to the rolling direction and the loading conditions are reported in Table 1. Sixty specimens were tested under each loading condition.

2.2. Virkler et al.'s Data [48]. The experimental activity reported by Virkler et al. [48] was aimed at determining which crack growth rate calculation method yields the least amount of error when the crack growth rate curve is integrated back to obtain the original " $a$ " versus " $N$ " curve data. Crack growth tests were carried out on $68 \mathrm{M}(T)$ specimens, made of aluminium alloy 2024-T3 and having a thickness of $2.54 \mathrm{~mm}$. All tests were conducted under the cyclic load with a maximum value of $5.25 \mathrm{kip} / 23.35 \mathrm{kN}$ and a minimum load of $1.05 \mathrm{kip} / 4.67 \mathrm{kN}$ at $R=0.2$.

2.3. Wu and Ni's Data [49]. The experimental work of Wu and $\mathrm{Ni}$ [49] was carried out on compact tension $\mathrm{C}(T)$ specimens made of aluminium alloy 2024-T351, having thickness $B=$ $12 \mathrm{~mm}$ and width $W=50 \mathrm{~mm}$. Tests were carried out with variable and constant amplitude loading. The two samples marked by the authors as CA1 and CA 2 and composed of 30 and 10 specimens, respectively, were tested at constant amplitude loadings reported in Table 2.

\section{Model Implementation}

The analysis of experimental data obtained from FCG test is quite complex due to the scatter nature in the raw data which is amplified by the derivation needed to compute the FCG rate. Several useful formulae to fit the experimental data with the aim of a better, smoother curve have been proposed and reported in the literature. Among those, the use of a polynomial function to fit the raw data gives the possibility of obtaining a single numerical expression of the crack growth rate valid in the entire data range [46]. The choice of the most appropriate function can be made considering that the crack growth is exponential by nature. In mathematical terms, an exponential correlation can be represented introducing logarithmic functions for the crack length [50-52]. This linear correlation $(\log (a)$ versus $N)$ can be represented on a semilogarithmic plane as a straight line. There are models proposed in the literature which are developed adopting an exponential structure [52]. However, the trend identified using the experimental FCG data changes as the crack 
length approaches the failure condition. This consideration is supported by the presence of three different regions in the sigmoidal curve with each of them following a different trend. On the basis of the aforementioned observations, the most suitable formula to fit the whole FCG experimental data points can be deduced by summating the individual effects of the different crack growth regions [53]. Therefore, the following model, on the basis of a trial-and-error method, could be established:

$$
a(\tau)=h \cdot \tau^{p}+a_{\mathrm{th}} \cdot e^{\left(\tau^{\alpha} /\left(\beta-\tau^{\alpha}\right)\right)},
$$

where $\alpha, \beta$, and $p$ are three parameters to be determined by the least-square method. The procedure to derive the values corresponding to $h$ and $a_{\mathrm{th}}$ is described in later parts of this paper. The proposed model makes use of nondimensional fatigue crack life, which makes it more general. Moreover, the nondimensional fatigue crack life allows decoupling the identification of the equation parameters, which are meant to be a material property, from the actual total life for the particular test. The nondimensional fatigue life $\tau$ is defined as follows:

$$
\tau=\frac{N+N_{\mathrm{th}}}{N_{f}+N_{\mathrm{th}}}
$$

The parameter $N_{\text {th }}$, which is identified through best-fit curve together with three parameters $(\alpha, \beta$, and $p)$ reported above, is related to the nucleation phase and hence to the threshold value. $N_{f}$ is the final value of the experimental crack life, which is the number of cycles counted from the initial crack length up to the final failure of the specimen, whilst $N$ is the generic value of the fatigue crack life.

Useful formulae can be derived for other parameters in (3) by considering some specific data points of the crack growth curve. At $N=N_{f}$, which corresponds to the last experimental data point of the test, the crack length is equal to the value of the crack length $a_{f}$ in the corresponding last front just before the failure condition of the specimen. This gives

$$
h=a_{f}-a_{\mathrm{th}} \times e^{(1 /(\beta-1))} .
$$

Similarly, considering the value of (3) at $N=0$, which corresponds to the first experimental data point, the crack length is equal to the value of the crack length $a_{\text {th }}$ corresponding to the starting point of the test. This gives

$$
a_{\mathrm{th}}=\frac{a_{\mathrm{th}}-a_{f} \times\left(N_{\mathrm{th}} /\left(\mathrm{th}+N_{f}\right)\right)^{p}}{e^{\left(N_{\mathrm{th}} /\left(N_{f}+N_{\mathrm{th}}\right)\right)^{\alpha} /\left(\beta-\left(N_{\mathrm{th}} /\left(N_{f}+N_{\mathrm{th}}\right)\right)^{\alpha}\right)}-\left(N_{\mathrm{th}} /\left(N_{f}+N_{\mathrm{th}}\right)\right)^{p} \times e^{(1 /(\beta-1))}} .
$$

As already stated, the parameter $N_{\text {th }}$ is related to the threshold condition and represents the number of cycles needed by the crack to reach the crack length corresponding to the threshold condition. From (3), the crack length in correspondence to the threshold condition is equal to the value of the $a_{\text {th }}$ parameter in correspondence of $N=-N_{\text {th }}$.

Equation (3) is a continuous differentiable function in the range $N_{\text {th }}<N<N_{f}$. It is therefore possible to derive the analytical expression of the crack growth rate $(d a / d N)$ as a function of $N$. The function (see (7)) can be used to represent the continuous propagation process from threshold region up to the final fast crack growth region

$$
\begin{aligned}
& \frac{d a}{d N(N)}=\frac{h\left(\left(N+N_{\mathrm{th}}\right) /\left(N_{f}+N_{\mathrm{th}}\right)\right)^{p} p}{N+N_{\mathrm{th}}} \\
& +a_{\mathrm{th}}\left(\frac{\left(\left(N+N_{\mathrm{th}}\right) /\left(N_{f}+N_{\mathrm{th}}\right)\right)^{\alpha} \alpha}{\left(N+N_{\mathrm{th}}\right)\left(\beta-\left(\left(N+N_{\mathrm{th}}\right) /\left(N_{f}+N_{\mathrm{th}}\right)\right)^{\alpha}\right)}\right. \\
& \left.+\frac{\left(\left(\left(N+N_{\mathrm{th}}\right) /\left(N_{f}+N_{\mathrm{th}}\right)\right)^{\alpha}\right)^{2} \alpha}{\left(\beta-\left(\left(N+N_{\mathrm{th}}\right) /\left(N_{f}+N_{\mathrm{th}}\right)\right)^{\alpha}\right)^{2}\left(N+N_{\mathrm{th}}\right)}\right) \\
& \cdot e^{\left(\left(N+N_{\mathrm{th}}\right) /\left(N_{f}+N_{\mathrm{th}}\right)\right)^{\alpha} /\left(\beta-\left(\left(N+N_{\mathrm{th}}\right) /\left(N_{f}+N_{\mathrm{th}}\right)\right)^{\alpha}\right)} .
\end{aligned}
$$

The parameters in the crack growth rate function are identified by means of the linear regression using the FCG raw data. The analytical expression of the crack growth rate is equal to zero at $N=-N_{\text {th }}$ according to the assumption that the crack length at this value corresponds to the threshold condition.

The procedure of applying the formulae of the analytical model to derive the threshold SIF range is as follows:

(i) The experimental raw data of crack length versus number of cycles are fitted using (3). The method adopted for the fitting is the linear regression to identify the four parameters of $N_{0}, \alpha, \beta$, and $p$ and minimize the error. In an earlier paper [53], the model here presented was adopted to assess the accuracy in fitting the raw data produced during FCG tests. In the same paper [53], the normal distribution of the residuals as well as the distribution of the equation parameters has been included. In the present paper, the discussion is focused on the identification of the threshold SIF range through the use of the analytical model proposed by the authors.

(ii) After the identification of the four parameters $N_{0}, \alpha$, $\beta$, and $p$, the values of the other two parameters $h$ and $a_{\text {th }}$ can be computed.

(iii) Identify the six parameters used in the analytical formula representing the crack length as a function 


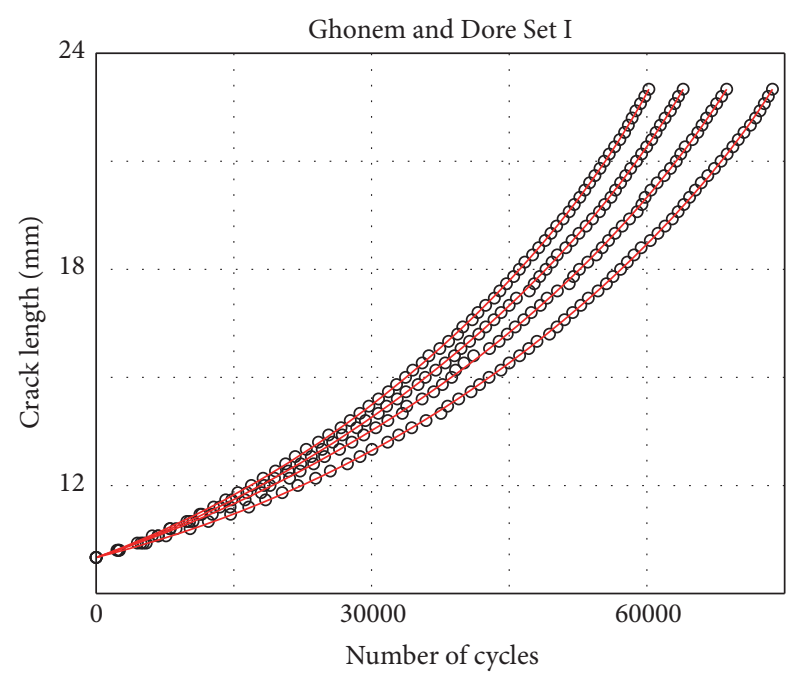

FIGURE 2: Four sets of crack growth data from Ghonem and Dore's dataset [47]: raw data (dots) and analytical model (lines).

of the fatigue crack life as well as the corresponding function of the crack growth rate.

(iv) A vector in the range $\left[-N_{\mathrm{th}} ; N_{f}\right]$ composed of $n$ values is generated. For each value of the vector defined above, the corresponding values of the crack length and the crack growth rate are determined using (3) and (7). The crack length values derived from (3) are used to deduce the SIF range values by means of the expressions in accordance with the international standards. This means that the method requires the knowledge of the closed form of the SIF for the tested specimen. In this paper, the expressions reported by the ASTM E647 [24] have been used to compute the SIF values.

(v) The value of the crack length corresponding to $N=$ $-N_{\text {th }}$ is used to derive the value of the threshold SIF range which corresponds to a crack growth rate equal to zero.

The procedure described above has been implemented in a Matlab code to identify the FCG curves and the $\Delta K_{\text {th }}$ values using the datasets produced by Ghonem and Dore, Virkler, and $\mathrm{Wu}$ and Ni. The detailed discussion about the capability of the model to properly fit the datasets used in this paper is given in an earlier paper [53]. Figure 2 shows some examples of fitting results with the experimental points related to Set I produced by Ghonem and Dore.

Moreover, normality of the residuals obtained from each curve has been verified by the $\chi^{2}$ normality tests and the corresponding residuals frequency histograms have also been evaluated. In Figure 3, the means of residuals for Ghonem and Dore Set I and Set III are shown as an example to highlight the notion that the mean value is equal to zero [53].

A further version of the Matlab code, which was already implemented for the fitting curves, was developed further in order to identify the values of the FCG rate as well as the SIF range values. In particular, the SIF values in correspondence to $N=-N_{\text {th }}$ for each curve of all datasets have been computed in order to estimate the threshold values and compare these with those reported in the literature.

\section{Results and Analyses}

The interpolation of the raw experimental data represents the first step of the analysis. The suitability of the equation for fitting the data has been summarised in the above section. In particular, raw data fitting has an average value of $R^{2}$ equal to 0.9998 for all datasets [53]. The values of the parameters identified for each dataset are shown in Table 3

The values reported in Table 3 have been computed as an average of the values identified over the total number of tests for each dataset.

The crack length as a function of the number of cycles derived in the range $\left[-N_{\text {th }} ; N_{f}\right]$ is shown for each dataset in Figure 4. In particular, the curve fitting related to the three datasets produced by Ghonem and Dore is shown in the top row of Figure 4 (Set I, Set II, and Set III), and the curves related to the dataset produced by Virkler and the curves related to the datasets produced by $\mathrm{Wu}$ and $\mathrm{Ni}$ are shown in the bottom row of Figure 4. In each dataset, all the fitting curves tend to the same asymptotic value as the number of cycles approaches $-N_{\mathrm{th}}$. However, the values are different between the various datasets. In order to make the comparison between the experimental data points and the curves identified with the analytical model possible, the logarithmic plot of the horizontal axis, which is the number of cycles, has been used. The logarithmic scale is only used for the sake of clarity of the graph whilst the equations adopted are not affected by this choice.

In order to draw the FCG curve for the entire range, it is necessary to derive the crack growth rate together with the SIF range for the corresponding values. The curves shown in Figure 5 correspond to all experimental data of the datasets considered in this paper. These graphs show clearly that the gradient approaching $N=-N_{\text {th }}$ is equal to zero, which reflects the asymptotic behaviour in the $a-N$ curves. As a consequence, the FCG rate, as expected, approaches zero.

This observation can be used to extrapolate the crack growth curve from the lower part. The value of the threshold SIF range is found where $N=-N_{\text {th }}$. By means of (3), the value of the crack length at $N=-N_{\text {th }}$ can be derived. In Figure 6 , the values of the threshold SIF predicted by the model for each curve of the five datasets analysed in this paper are shown together with the corresponding values gathered from the literature [44].

\section{Discussions}

The curves of crack length versus number of cycles found from the model correlate well with the raw data points. To relate the parameter values obtained by means of the best fit to the testing conditions, the contour plots shown in Figure 7 have been created. The contour plots can be used to identify the range in which the optimal values of the model parameters should be identified by means of the best fit of the experimental raw data in terms of crack length versus 


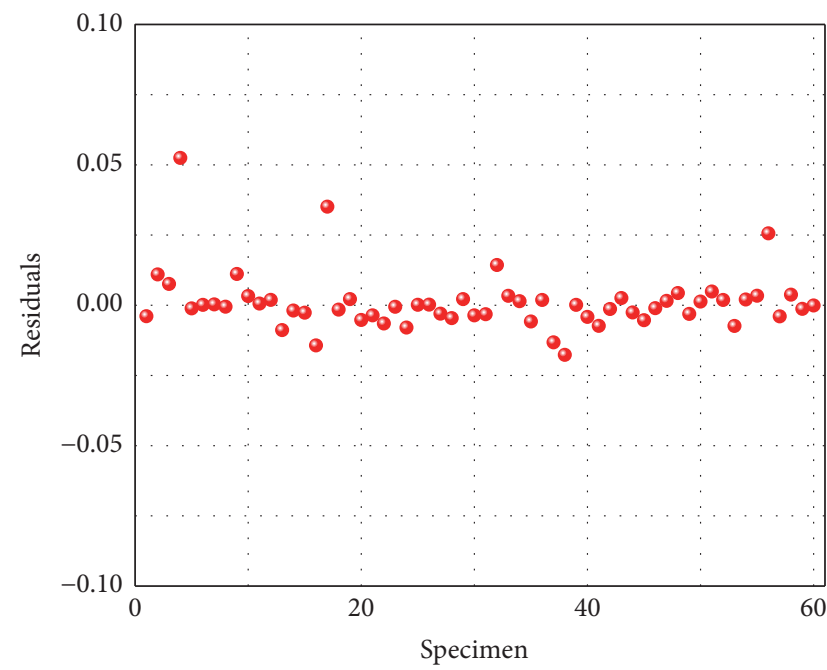

(a)

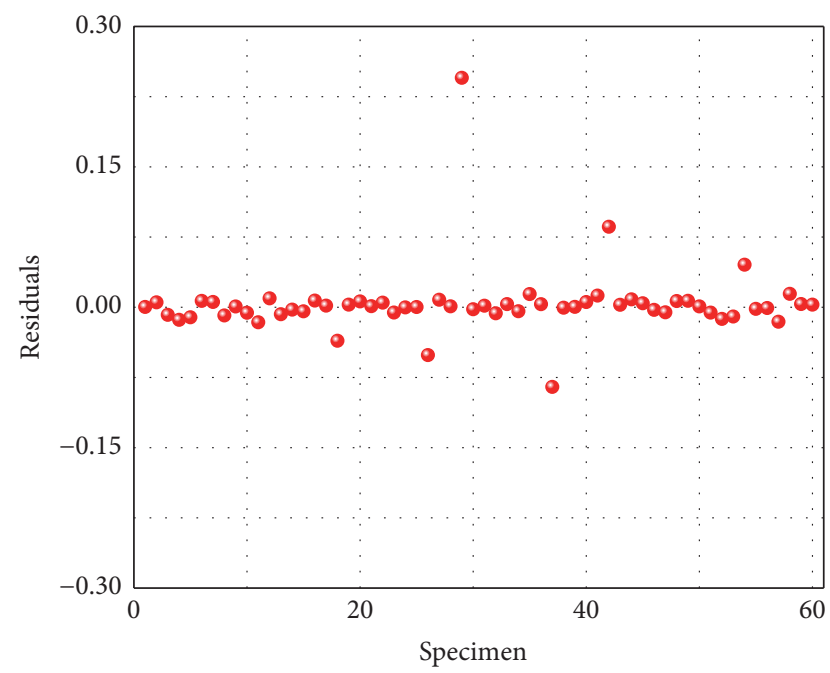

(b)

FIgURE 3: Mean of residuals obtained by fitting Ghonem and Dore Set I (a) and Ghonem and Dore Set III (b).
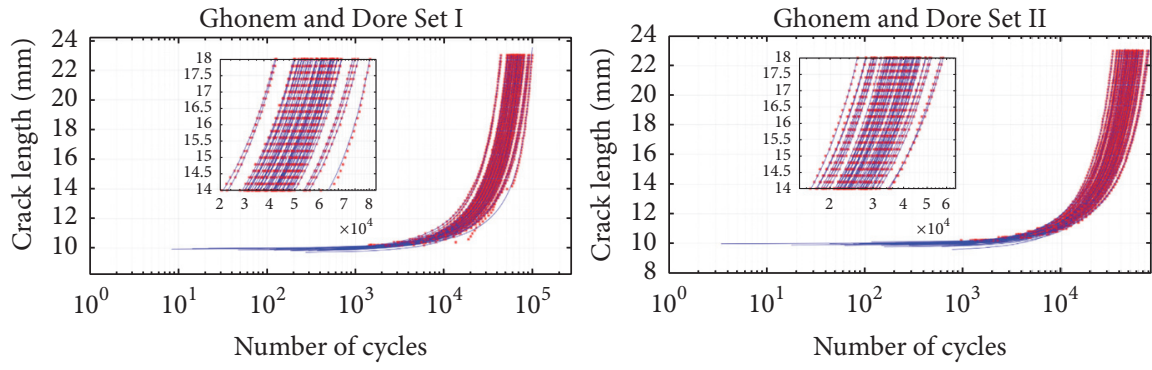

(a)
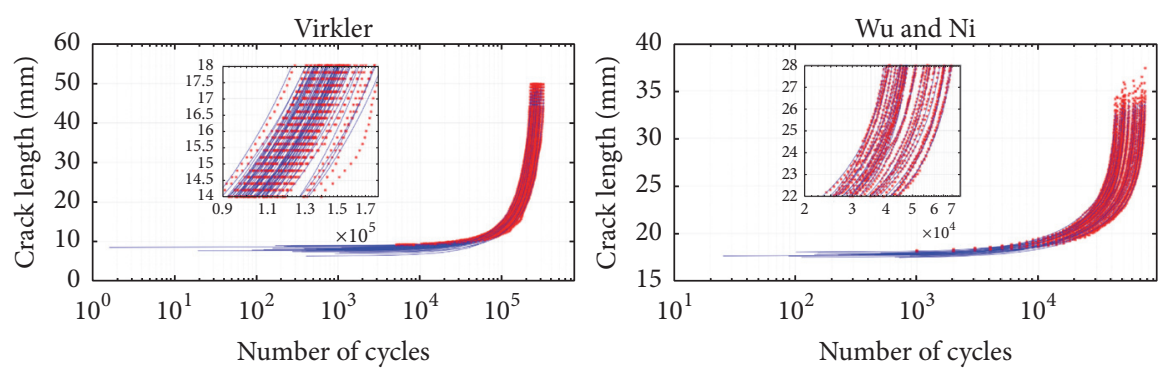

(b)

TABle 3: Parameter values for the five datasets.

\begin{tabular}{lccccccc}
\hline & $\alpha$ & $\beta$ & $N_{\text {th }}$ & $p$ & $h$ & $a_{\text {th }}$ & $\Delta K_{\text {th }} \mathrm{MPa} \sqrt{\mathrm{m}}$ \\
\hline Ghonem and Dore Set I & 1.91 & 1.34 & 914314 & 4.40 & 6.75 & 0.81 & 1.42 \\
Ghonem and Dore Set II & 1.69 & 1.33 & 695502 & 3.43 & 6.33 & 0.72 & 1.63 \\
Ghonem and Dore Set III & 4.73 & 1.53 & 1635716 & 4.58 & 6.38 & 1.57 & 1.90 \\
Virkler & 2.93 & 1.28 & 2211197 & 6.59 & 19.84 & 0.75 & 2.79 \\
Wu and Ni & 58.04 & 1.85 & 842999 & 6.45 & 21.25 & 3.65 & 3.61 \\
\hline
\end{tabular}



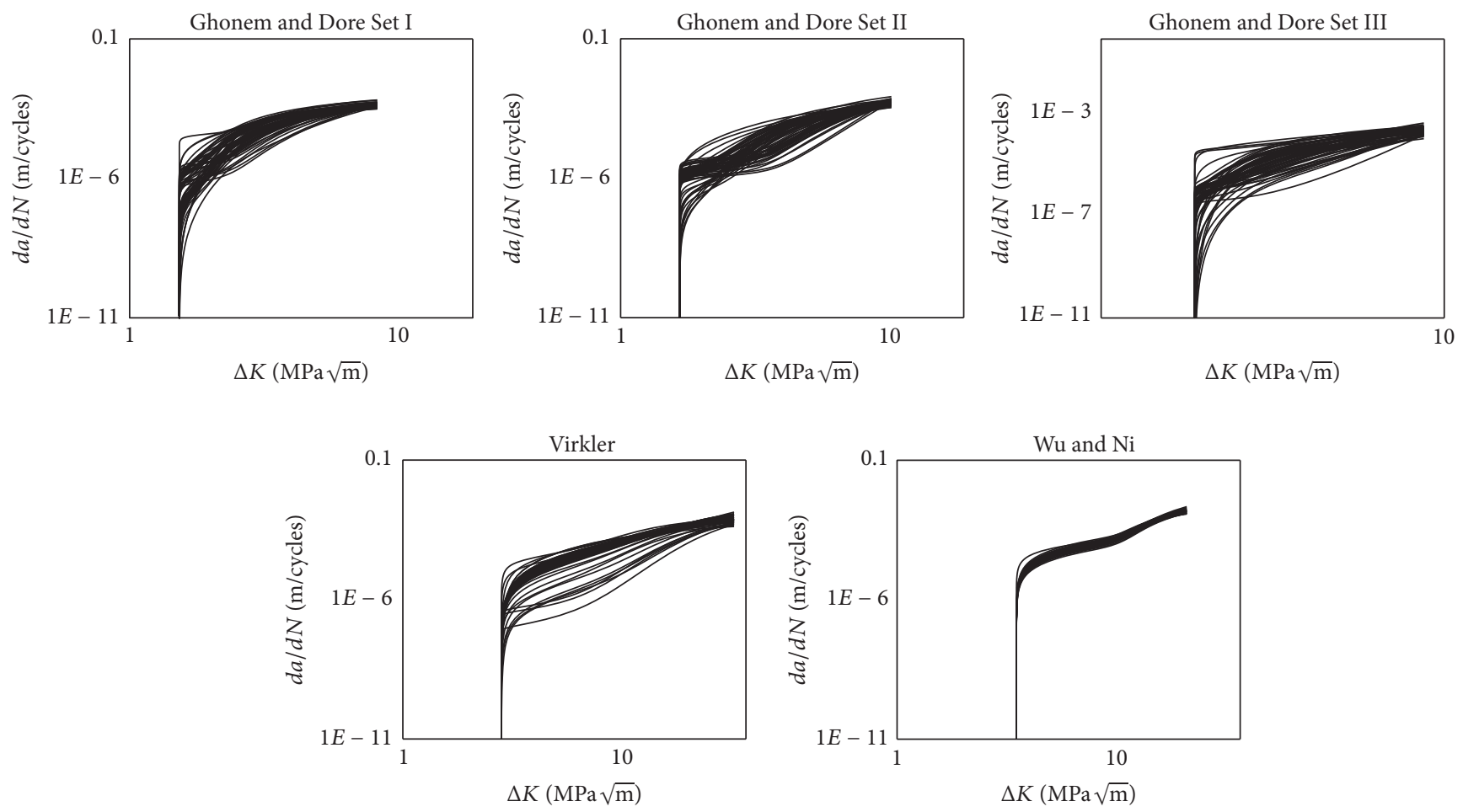

Figure 5: FCG curve for the five datasets.

number of cycles. Nevertheless, the possibility of correlating the model parameters with the loading conditions by means of analytical expression can be adopted. This would allow us to either reduce the number of parameters that can be identified through the best fit or identify the FCG curve for a given material under certain loading conditions, which are usually defined in terms of maximum load and load ratio. For this reason, the correlations between the 6 parameters of the proposed model and the maximum load $P_{\max }$ and the load ratio $R$ have been investigated using the values obtained from the fitting analysis carried out with the datasets found in the literature and already discussed in this paper. In (Figures 7 and 8), $P_{\max }$ is defined as the maximum value of the applied load in each cycle.

The two parameters $\alpha$ and $\beta$ and $a_{\text {th }}$ depend on the load ratio for low values of the maximum applied load only. At higher values of the maximum applied load, the range of the above parameters is the same whatever the load ratio is, which means they are independent of the load ratio. Moreover, their values decrease as the values of $R$ and $P_{\max }$ increase. A different trend can be observed from referring to the model parameters of $N_{\text {th }}, p$, and $h$. The combined effect of the load ratio and the maximum applied load is always present for the investigated range values of the loading conditions. In addition, the values of the two parameters $p$ and $h$ decrease as the values of $R$ and $P_{\max }$ increase, whilst for $N_{\text {th }}$ the trend is opposite with regard to $P_{\max }$. In the graphs shown in Figure 8, the correlations identified between the model parameters and the loading conditions are shown. In some cases, the combination of more than one parameter has been considered.
In particular, for $h, N_{\text {th }}$, and $p$, three different expressions have been introduced:

$$
\begin{aligned}
& C_{1}=\frac{h P_{\min }}{a_{0}}, \\
& C_{2}=\frac{N_{\mathrm{th}}}{N_{0}}, \\
& C_{3}=\frac{p a_{f}}{P_{\min }} .
\end{aligned}
$$

Expressions reported as (8) and (10) have been shown to be related to the maximum applied load, as shown in Figure 8. Equation (9) is related to the load ratio and it is shown in Figure 8. In terms of the quality of fit, it can be assessed with the value of the coefficient of correlation $\left(R^{2}\right)$. Good fitting is achieved if the coefficient of correlation is between 0.8 and 1 for all the correlations identified [54]. $N_{\text {th }}$ in function of $P_{\max }$, as shown in Figure 8, has lower coefficient of determination of 0.8286 in the current study. This value is however still within the acceptable range and the correlation between the considered parameters values is acceptable.

The extrapolation of the curves as shown in Figure 5 reaches $N=-N_{\text {th }}$ asymptotically, which can be used to generate $\Delta K_{\text {th }}$ values based on the theory of identifying threshold $[19,21]$. The range between the maximum and the minimum values of the predicted $\Delta K_{\text {th }}$ for each dataset is quite small so that the average value of the threshold is used. The reference values for materials considered in this paper have been taken from the literature in order to verify the model. In the literature, a range of threshold values are 

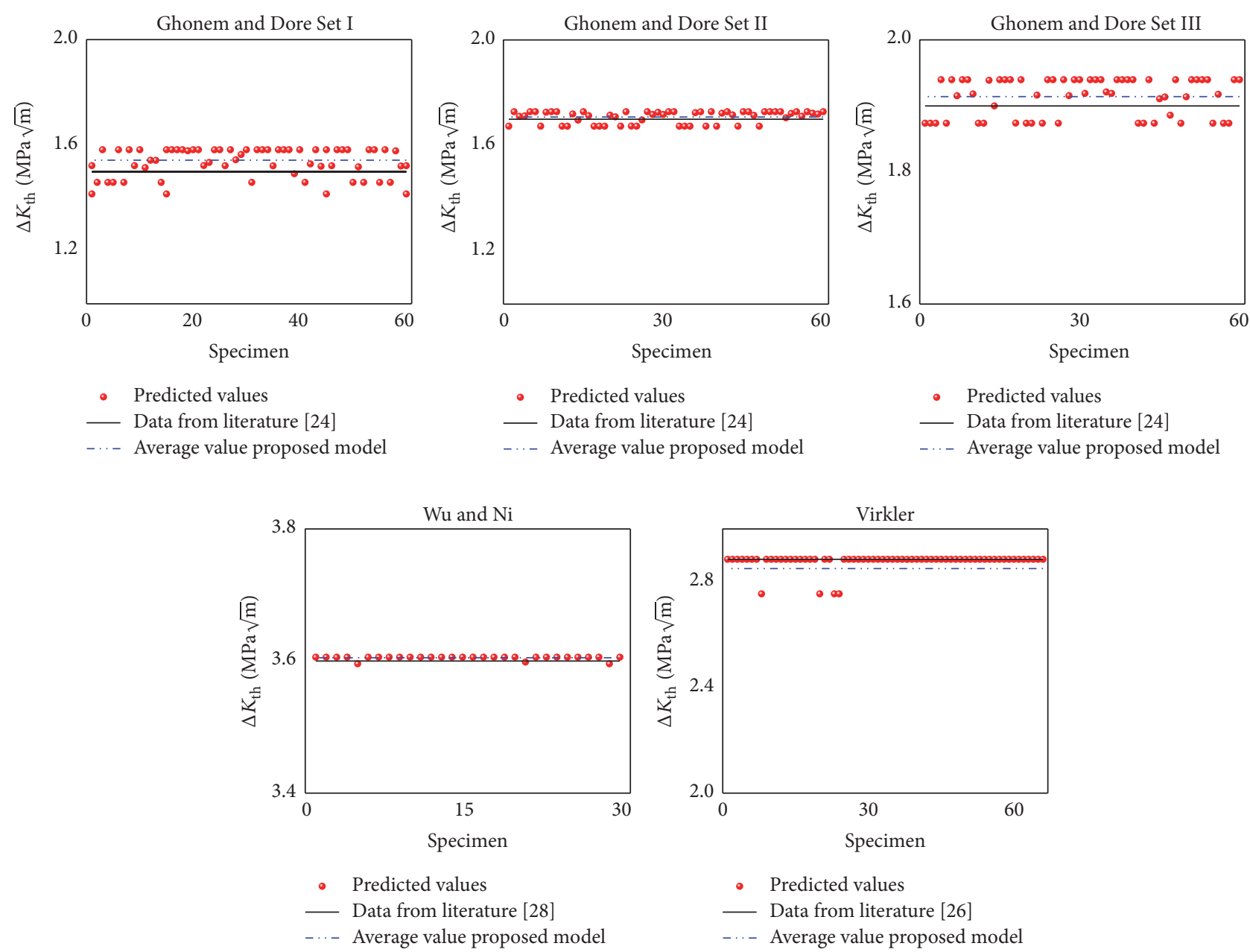

FIGURE 6: Threshold SIF range for the five datasets.

also mentioned for a particular material for a constant $R$ $[18,41,55]$. Figure 10 shows the comparison between the threshold values obtained using the model and threshold values found in the literature for the same kind of material. The values considered as literature values are based on ESDU documents [41] for aluminium alloy 7075-T6 (at $R=0.4$, 0.5 , and 0.6 ) and aluminium alloy 2024-T3 (at $R=0.2$ ). For 2024-T351 (at $R=0.2$ ), the literature value is taken based on $\Delta K_{\text {th }}$ value provided by [44] and normalized threshold SIF range against $R$ curve provided by [43]. The average threshold value of the model is used for the comparison. In Ghonem and Dore (Sets I-III), Virkler, and $\mathrm{Wu}$ and $\mathrm{Ni}$ datasets, the threshold values of the corresponding materials from the literature are $1.5 \mathrm{MPa} \sqrt{\mathrm{m}}, 1.7 \mathrm{MPa} \sqrt{\mathrm{m}}, 1.9 \mathrm{MPa} \sqrt{\mathrm{m}}$, $2.85 \mathrm{MPa} \sqrt{\mathrm{m}}$, and 3.6 $\mathrm{MPa} \sqrt{\mathrm{m}}$. Comparing these values with those predicted by the proposed model, the percentages of error are approximately $5.3 \%, 4.1 \%, 0 \%, 2.1 \%$, and $0.3 \%$, respectively.

As shown earlier in Figure 6, in all cases, there is a band of threshold values predicted for the same material with the literatures showing the same trends. The threshold versus $R$ graph provided by [41] shows a small range of threshold values with upper and lower limit indicated for 2024-T3 aluminium alloy. Different investigations by Newman Jr. and Ruschau [1, 2, 28-30] also found a range of thresholds based on different experimental methods used, for example, load reduction (LR) methods, $K_{\max }$ constant methods, and farfield cyclic compression methods.

Recently, Molent and Jones [18] used a FCG threshold parameter $\Delta K_{\text {thr }}$ to explain the scatter in the fatigue life prediction. $\Delta K_{\text {thr }}$ is used to explain the dependency of the threshold values on the material properties, $R$ ratio, crack length, and loading method used for the testing phase. From the literature $[45,56]$, it was found that $\Delta K_{\mathrm{thr}}=$ 0 produces conservative crack growth predictions for different aluminium alloys. The fact that different values of the threshold SIF were reported for the same material in the literature can be treated as supporting evidence to the concept of cyclic stress intensity threshold. For the material with which the samples used by Virkler were made, a range of $\Delta K_{\text {thr }}(2.9 \div 4.2 \mathrm{MPa} \sqrt{\mathrm{m}})$ is reported in the literature, whilst, in the material used by $\mathrm{Wu}$ and $\mathrm{Ni}$, a range of $\Delta K_{\text {thr }}(0 \div 4.2 \mathrm{MPa} \sqrt{\mathrm{m}})$ is reported. Moreover, for 7075-T6 aluminium alloy material at $R=-1$, the range of $\Delta K_{\text {thr }}(0.6 \div$ $1.13 \mathrm{MPa} \sqrt{\mathrm{m}}$ ) was found in the literature. In other published papers [55], a threshold band $\Delta K_{\mathrm{thr}}(2.8 \div 4 \mathrm{MPa} \sqrt{\mathrm{m}})$ at 

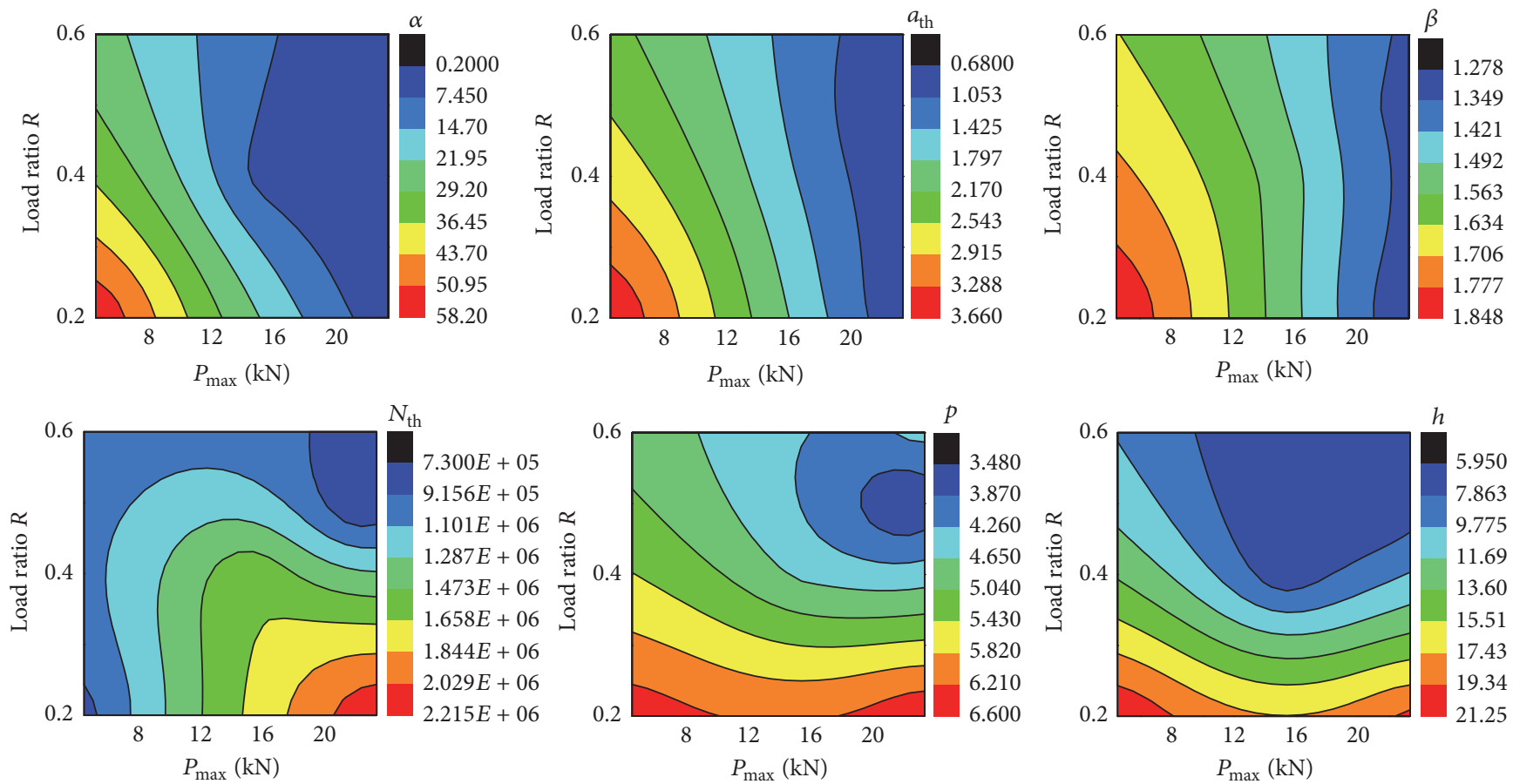

FIGURE 7: Contour plot of the model parameter average values in function of the loading conditions.

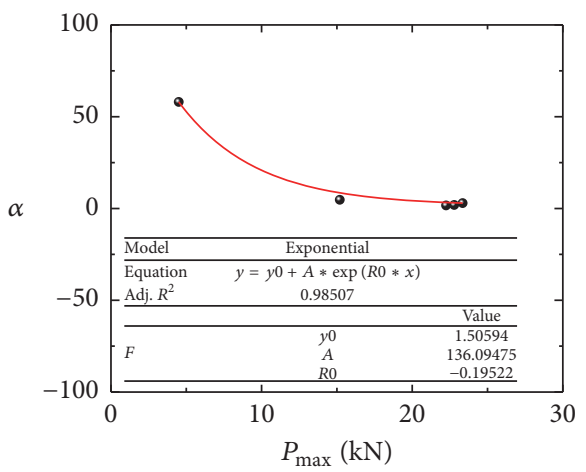

- Experimental data point — Best fit

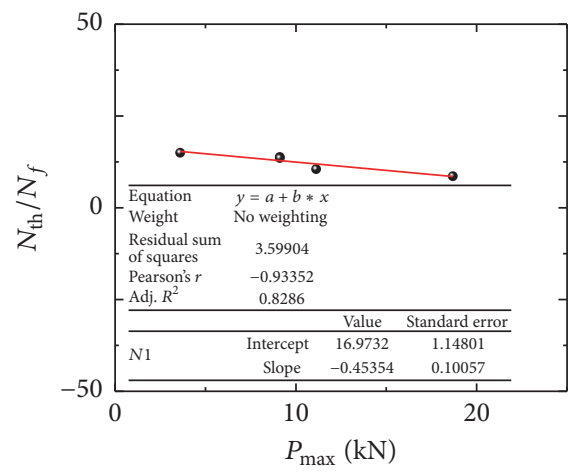

- Experimental data point — Best fit

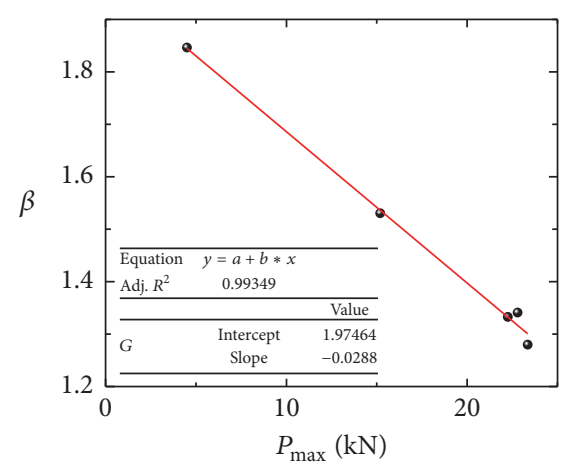

- Experimental data point — Best fit

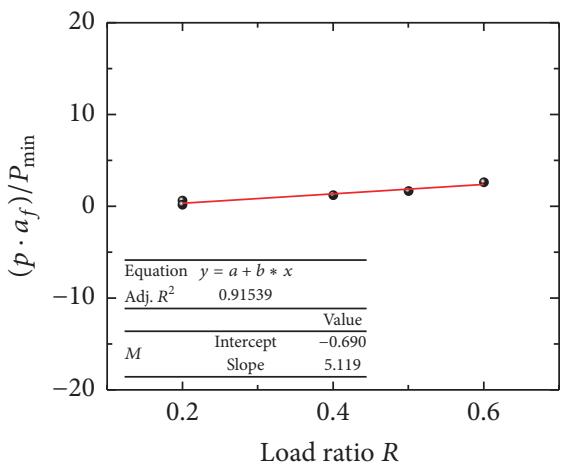

- Experimental data point Best fit

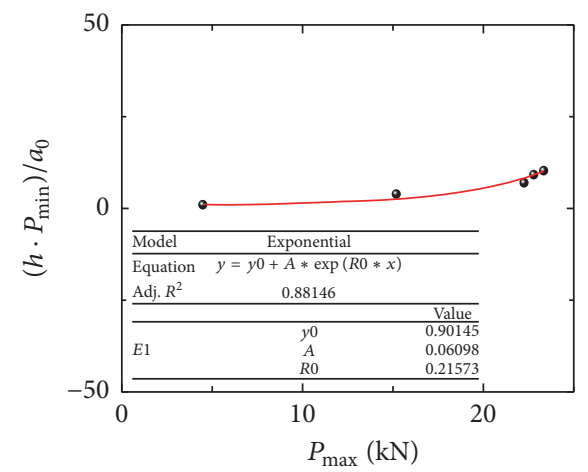

- Experimental data point — Best fit

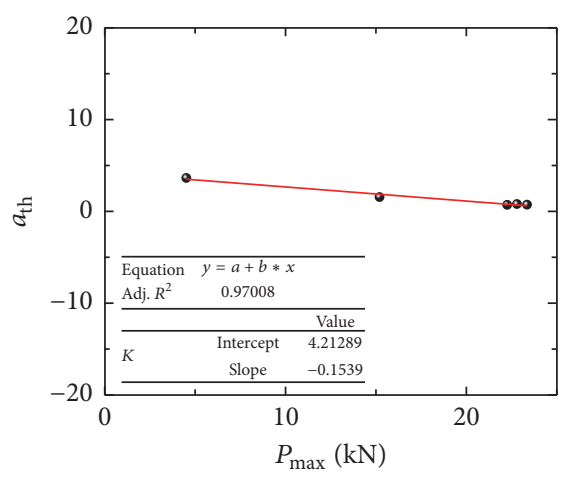

- Experimental data point Best fit

FIGURE 8: Best fit of the model parameters values in function of loading conditions. 


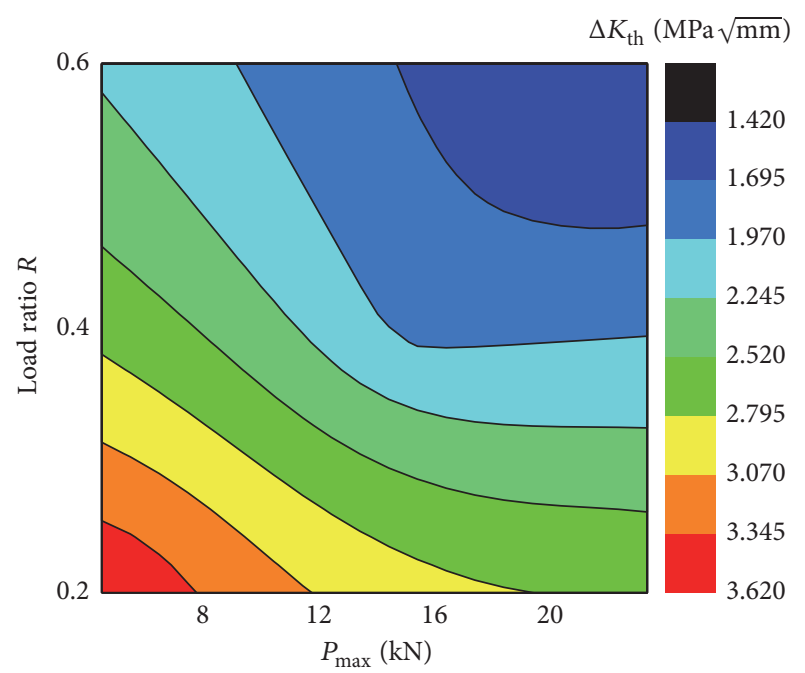

FIGURE 9: Contour plot of $\Delta K_{\mathrm{th}}$ in function of the maximum applied load and the load ratio.

$R=0.33$ for 2024-T351 aluminium alloy has been shown. All these values are in good agreement with those estimated by the proposed model.

In order to investigate the variability of the threshold SIF range, the response surface reporting the correlation of this latter parameter as functions of the maximum applied load and the load ratio is shown in Figure 9. The values shown in the graph related to the threshold SIF are those identified through the fitting analysis of the raw data. Although all the values identified in the analysis related to different aluminium alloys are shown on the same plot, the validity of the contour plot is limited to the $R$ and $P_{\max }$ ranges investigated in this paper and the alloys considered in the tests are referring to the datasets used for the analysis. However, the contour can represent a valid tool for a preliminary identification of the threshold SIF range.

Reporting all the results on the same graph in Figure 10, it is possible to identify the common trend useful to compare the results with the literature values. Firstly, the threshold line found with declined linear pattern or shape in relation to $R$ for the 7075-T6 aluminium alloy is qualitatively and quantitatively consistent with the line found in the literature [41]. The percentage of error ranges between $0.24 \%$ and $5.61 \%$, which is quite low considering the scattering nature of the fatigue test data. The threshold SIF range values should converge at the higher value of $R$ but it was found that the scatter was getting bigger and reached 5.61\% at $R=0.6$. This difference or scatter could be explained by different experimental methods used and the corresponding crack closure effects as referred by [1, 2, 28-30]. All the predicted threshold values of aluminium alloys (7075-T6 and 2024T6) underestimate the values from the literature (see, e.g., [41]) except for the threshold value of 2024-T351 aluminium alloy which overestimates the literature value from $[43,44]$. For 7076-T6 aluminium alloy, the threshold value from the literature [3] at $R=0.2$ is $2.3 \mathrm{MPa} \sqrt{\mathrm{m}}$ whilst the value

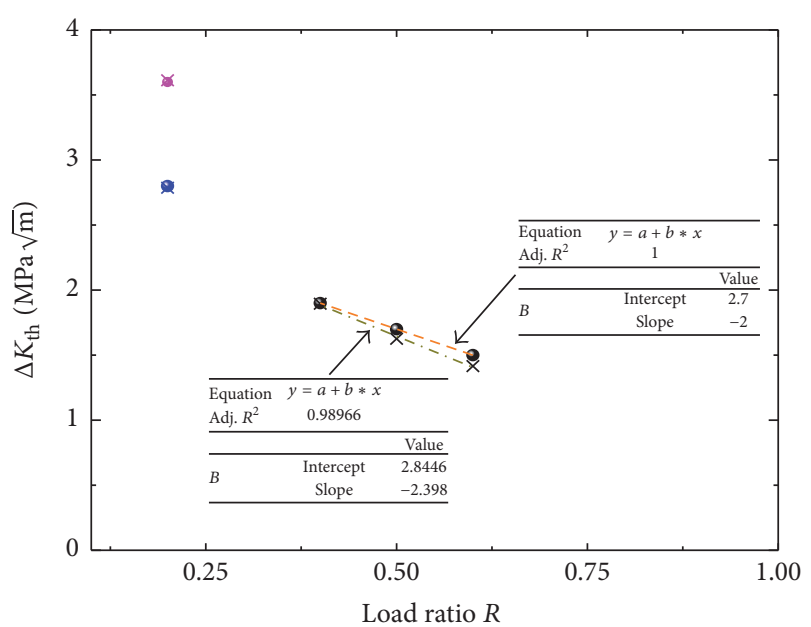

- Threshold of Al alloy 7075-T6 from [41]

- Threshold of Al alloy 2024-T3 from [41]

- Threshold of Al alloy 2024-T351 from [43, 44]

$\times \quad$ Threshold of Al alloy 7075-T6 from model

$\times \quad$ Threshold of Al alloy 2024-T3 from model

$\times \quad$ Threshold of Al alloy 2024-T351 from model

-.. Linear regression AL7075-T6 predicted data points

- - - Linear regression AL7075-T6 data points from literature

FIgURE 10: Threshold versus load ratio data where thresholds of model and literature are compared.

derived using the analytical model here proposed is equal to $2.3651 \mathrm{MPa} \sqrt{\mathrm{m}}$ with an error less than $3 \%$.

In general, the yield strength of 7075-T6, 2024-T3, and 2024-T351 aluminium alloys is $510 \mathrm{MPa}, 350 \mathrm{MPa}$, and $330 \mathrm{MPa}$, respectively. The threshold values found from the model for the three alloys at $R=0.2$ are $3.6 \mathrm{MPa} \sqrt{\mathrm{m}}$, 2.8 $\mathrm{MPa} \sqrt{\mathrm{m}}$, and $2.4 \mathrm{MPa} \sqrt{\mathrm{m}}$, respectively. This indicates a correlation between the yield strength and threshold of these aluminium alloys: higher strength aluminium alloy possesses relatively higher threshold and vice versa. This supports the statement of the previous investigations which found the same type of correlation between the strength and threshold of materials [19, 36, 37].

It should be added that the values of $a_{\text {th }}$ in (6) were found to influence the threshold value since it is the value of the crack length corresponding to the fatigue life value equal to $N=-N_{\text {th }}$. Therefore, $a_{\text {th }}$ values can be further considered to correlate with the material properties and the load ratio as well as the geometry of the cracked component. It is possible to find in the literature that the threshold value increases with the strength of the material $[19,36,37]$. Further research should be carried out to properly address this correlation, which could help in both identifying the parameter values and giving them a more physical meaning.

\section{Conclusions}

An analytical model for the interpolation of crack propagation data has been developed. The threshold SIF range 
has been derived for different materials and different specimen geometries. The new model has been shown to fit, with the needed accuracy, to a wide range of experimental data produced with different specimen geometries, different materials, and different loading conditions. Moreover, it has been highlighted that it is possible to identify, by means of the above model, the value of the threshold SIF range with an error, as compared to the values reported in the literature, of less than $6 \%$. The relation between $\Delta K_{\text {th }}$ and $R$ ratio predicted by the model agrees well with the literature results. The proposed model can therefore be valuable in identifying the threshold of stress intensity factor range for fatigue crack growth.

\section{Nomenclature}

\begin{tabular}{|c|c|}
\hline$a:$ & Crack length (mm) \\
\hline$a_{f}:$ & $\begin{array}{l}\text { Final value of the experimental } \\
\text { crack length }(\mathrm{mm})\end{array}$ \\
\hline$B:$ & Specimen thickness (mm) \\
\hline$C, p, q, m:$ & Forman's constants \\
\hline$d a / d N:$ & Crack growth rate (mm/cycle) \\
\hline$h, \tau, p, a_{\mathrm{th}}, \alpha, \beta, N_{\mathrm{th}}:$ & $\begin{array}{l}\text { Parameters of the model proposed } \\
\text { in the present paper }\end{array}$ \\
\hline$K_{C}:$ & Fracture toughness $(\mathrm{MPa} \sqrt{\mathrm{mm}})$ \\
\hline$K_{\max }:$ & $\begin{array}{l}\text { Maximum value of the stress } \\
\text { intensity factor }(\mathrm{MPa} \sqrt{\mathrm{mm}})\end{array}$ \\
\hline$N:$ & Number of cycles \\
\hline$N_{f}:$ & $\begin{array}{l}\text { Final value of the experimental } \\
\text { crack life }\end{array}$ \\
\hline$P_{\text {max }}:$ & $\begin{array}{l}\text { Maximum value of the applied load } \\
(\mathrm{kN})\end{array}$ \\
\hline$P_{\min }:$ & $\begin{array}{l}\text { Minimum value of the applied load } \\
(\mathrm{kN})\end{array}$ \\
\hline$R:$ & Load ratio \\
\hline$R^{2}:$ & Coefficient of determination \\
\hline$W:$ & Specimen width $(\mathrm{mm})$ \\
\hline$\gamma:$ & $\begin{array}{l}\text { Material parameter for Klesnil and } \\
\text { Lukášs model }\end{array}$ \\
\hline$\Delta K:$ & $\begin{array}{l}\text { Range of the stress intensity factor } \\
(\mathrm{MPa} \sqrt{\mathrm{mm}})\end{array}$ \\
\hline$\Delta K_{\mathrm{th}}$ & $\begin{array}{l}\text { Value of the stress intensity factor } \\
\text { range threshold }(\mathrm{MPa} \sqrt{\mathrm{mm}})\end{array}$ \\
\hline$\Delta K_{\text {th } 0}:$ & $\begin{array}{l}\text { Value of the stress intensity factor } \\
\text { range threshold for } R=0 \\
(\mathrm{MPa} \sqrt{\mathrm{mm}}) \text {. }\end{array}$ \\
\hline
\end{tabular}

\section{Competing Interests}

The authors declare that there are no competing interests regarding the publication of this paper.

\section{References}

[1] J. Newman Jr., J. Schneider, A. Daniel, and D. McKnight, "Compression pre-cracking to generate near threshold fatiguecrack-growth rates in two aluminum alloys," International Journal of Fatigue, vol. 27, no. 10-12, pp. 1432-1440, 2005.

[2] J. C. Newman Jr., J. J. Ruschau, and M. R. Hill, "Improved test method for very low fatigue-crack-growth-rate data, Fatigue \&
Fracture of Engineering Materials and Structures, vol. 34, no. 4, pp. 270-279, 2011.

[3] M. Klesnil and P. Lukáš, "Influence of strength and stress history on growth and stabilisation of fatigue cracks," Engineering Fracture Mechanics, vol. 4, no. 1, pp. 77-92, 1972.

[4] J. Collipriest Jr., "An experimentalist's view of the surface flaw problem," in The Surface Crack-Physical Problems and Computational Solutions, pp. 43-61, ASME, New York, NY, USA, 1972.

[5] A. McEvily, "Phenomenological and microstructural aspects of fatigue," in The Microstructure and Design of Alloys, pp. 204-225, 1973.

[6] W. Johnson, "Multi-parameter yield zone model for predicting spectrum crack growth," in Methods and Models for Predicting Fatigue Crack Growth under Random Loading, ASTM International, 1981.

[7] J. Chang, "Round-robin crack growth predictions on centercracked tension specimens under random spectrum loading," in Methods and Models for Predicting Fatigue Crack Growth Under Random Loading, ASTM International, 1981.

[8] J. Newman, "Prediction of fatigue crack growth under variableamplitude and spectrum loading using a closure model," in Design of Fatigue and Fracture Resistant Structures, ASTM International, 1982.

[9] Z. Xiulin and M. A. Hirt, "Fatigue crack propagation in steels," Engineering Fracture Mechanics, vol. 18, no. 5, pp. 965-973, 1983.

[10] R. G. Forman and S. R. Mettu, "Behavior of surface and corner cracks subjected to tensile and bending loads in Ti-6Al-4V alloy," Tech. Rep., NASA, 1990.

[11] X. Huang and T. Moan, "Improved modeling of the effect of Rratio on crack growth rate," International Journal of Fatigue, vol. 29, no. 4, pp. 591-602, 2007.

[12] J. A. Harter, AFGROW Users Guide and Technical Manual, DTIC Document, 1999.

[13] J. C. Newman Jr., "FASTRAN-2: a fatigue crack growth structural analysis program," NASA STI/Recon Technical Report N 92, 1992.

[14] W. Hu and K. Walker, "Fatigue crack growth from a notch under severe overload and underload," in Proceedings of the International Conference on Structural Integrity and Failure, 2006.

[15] E. Castillo, A. Fernández-Canteli, and D. Siegele, "Obtaining S-N curves from crack growth curves: an alternative to selfsimilarity," International Journal of Fracture, vol. 187, no. 1, pp. 159-172, 2014.

[16] S. M. Beden, S. Abdullah, and A. K. Ariffin, "Review of fatigue crack propagation models for metallic components," European Journal of Scientific Research, vol. 28, no. 3, pp. 364-397, 2009.

[17] A. Hartman and J. Schijve, "The effects of environment and load frequency on the crack propagation law for macro fatigue crack growth in aluminium alloys," Engineering Fracture Mechanics, vol. 1, no. 4, pp. 615-631, 1970.

[18] L. Molent and R. Jones, "The influence of cyclic stress intensity threshold on fatigue life scatter," International Journal of Fatigue, vol. 82, part 3, pp. 748-756, 2016.

[19] U. Zerbst, M. Vormwald, R. Pippan, H.-P. Gänser, C. SarrazinBaudoux, and M. Madia, "About the fatigue crack propagation threshold of metals as a design criterion-a review," Engineering Fracture Mechanics, vol. 153, pp. 190-243, 2016.

[20] S. Suresh and R. O. Ritchie, "Propagation of short fatigue cracks," International Metals Reviews, vol. 29, no. 6, pp. 445-476, 1984. 
[21] T. L. Anderson, Fracture Mechanics: Fundamentals and Applications, Crc Press, 2005.

[22] P. Paris and F. Erdogan, "A critical analysis of crack propagation laws," Journal of Basic Engineering, vol. 85, no. 4, pp. 528-533, 1963.

[23] S. Pearson, "Initiation of fatigue cracks in commercial aluminium alloys and the subsequent propagation of very short cracks," Engineering Fracture Mechanics, vol. 7, no. 2, pp. 235247, 1975.

[24] ASTM International, Standard Test Method for Measurement of Fatigue Crack Growth Rates, ASTM International, 2011.

[25] S. Hudak Jr., A. Saxena, R. J. Bucci, and R. C. Malcolm, "Development of standard methods of testing and analyzing fatigue crack growth rate data," DTIC Document, DTIC, 1978.

[26] U. D.-I. M. Vormwald, "Elastic-plastic fatigue crack growth," in Advanced Methods of Fatigue Assessment, pp. 391-481, Springer, 2013.

[27] ISO, "Metallic materials-Fatigue testing-Fatigue crack growth method," Tech. Rep. 12108, British Standards Institution, London, UK, 2002.

[28] J. Ruschau and J. Newman, "Compression precracking to generate near threshold fatigue crack growth rates in an aluminum and titanium alloy," in Proceedings of the 7th International ASTM/ ESIS Symposium on Fatigue and Fracture Mechanics (36th ASTM National Symposium on Fatigue and Fracture Mechanics), ASTM International, 2009.

[29] J. C. Newman Jr. and Y. Yamada, "Compression precracking methods to generate near-threshold fatigue-crack-growth-rate data," International Journal of Fatigue, vol. 32, no. 6, pp. 879-885, 2010.

[30] S. C. Forth, J. C. Newman Jr., and R. G. Forman, "On generating fatigue crack growth thresholds," International Journal of Fatigue, vol. 25, no. 1, pp. 9-15, 2002.

[31] R. Pippan, "Threshold and effective threshold of fatigue crack propagation in ARMCO iron I: the influence of grain size and cold working," Materials Science and Engineering A, vol. 138, no. 1, pp. 1-13, 1991.

[32] S. Suresh, G. F. Zamiski, and D. R. O. Ritchie, "Oxide-induced crack closure: an explanation for near-threshold corrosion fatigue crack growth behavior," Metallurgical Transactions A, vol. 12, no. 8, pp. 1435-1443, 1981.

[33] J. Newman, "Fatigue and crack-growth analyses under gigacycle loading on aluminum alloys," Procedia Engineering, vol. 101, pp. 339-346, 2015.

[34] B. Li and L. G. Rosa, "Prediction models of intrinsic fatigue threshold in metal alloys examined by experimental data," International Journal of Fatigue, vol. 82, pp. 616-623, 2016.

[35] P. B. Chowdhury, H. Sehitoglu, and R. G. Rateick, "Predicting fatigue resistance of nano-twinned materials: Part II-effective threshold stress intensity factor range," International Journal of Fatigue, vol. 68, pp. 292-301, 2014.

[36] J. Wasén and E. Heier, "Fatigue crack growth thresholds-the influence of Young's modulus and fracture surface roughness," International Journal of Fatigue, vol. 20, no. 10, pp. 737-742, 1998.

[37] R. Pippan and P. Weinert, "The effective threshold of fatigue crack propagation in aluminium alloys II. The influence of particle reinforcement," Philosophical Magazine A, vol. 77, no. 4, pp. 875-886, 1998.

[38] I. Varfolomeev, M. Luke, and M. Burdack, "Effect of specimen geometry on fatigue crack growth rates for the railway axle material EA4T,' Engineering Fracture Mechanics, vol. 78, no. 5, pp. 742-753, 2011.

[39] D. Regazzi, I. Varfolomeev, S. Moroz, M. Luke, and S. Beretta, "Experimental and numerical investigations of fatigue crack closure in standard specimens. DVM-AK Bruchvorgänge," DVM-Bericht, vol. 245, pp. 157-166, 2013.

[40] P. Hutař, L. Náhlík, M. Ševčík, S. Seitl, T. Kruml, and J. Polák, "Fatigue crack propagation rate in EUROFER 97 estimated using small specimens," Key Engineering Materials, vol. 452-453, pp. 325-328, 2011.

[41] C. R. Hookham, "Fatigue crack propagation rates and threshold stress intensity factor ranges for aluminium alloy sheet," ESDU Fatigue-Fracture Mechanics Series 2000-03, 2000.

[42] B. L. Boyce and R. O. Ritchie, "Effect of load ratio and maximum stress intensity on the fatigue threshold in Ti-6Al4V," Engineering Fracture Mechanics, vol. 68, no. 2, pp. 129-147, 2001.

[43] S. Kwofie, "Equivalent stress approach to predicting the effect of stress ratio on fatigue threshold stress intensity range," International Journal of Fatigue, vol. 26, no. 3, pp. 299-303, 2004.

[44] R. Jones, L. Molent, and K. Walker, "Fatigue crack growth in a diverse range of materials," International Journal of Fatigue, vol. 40, pp. 43-50, 2012.

[45] X. R. Wu, J. C. Newman, W. Zhao, M. H. Swain, C. F. Ding, and E. P. Phillips, "Small crack growth and fatigue life predictions for high-strength aluminium alloys: Part I-experimental and fracture mechanics analysis," Fatigue and Fracture of Engineering Materials and Structures, vol. 21, no. 11, pp. 1289-1306, 1998.

[46] A. De Iorio, M. Grasso, F. Penta, and G. P. Pucillo, "A threeparameter model for fatigue crack growth data analysis," Frattura ed Integrità Strutturale, vol. 21, pp. 21-29, 2012.

[47] H. Ghonem and S. Dore, "Experimental study of the constantprobability crack growth curves under constant amplitude loading," Engineering Fracture Mechanics, vol. 27, no. 1, pp. 1-25, 1987.

[48] D. A. Virkler, B. M. Hillberry, and P. K. Goel, "The statistical nature of fatigue crack propagation," Journal of Engineering Materials and Technology, Transactions of the ASME, vol. 101, no. 2, pp. 148-153, 1979.

[49] W. F. Wu and C. C. Ni, "Statistical aspects of some fatigue crack growth data," Engineering Fracture Mechanics, vol. 74, no. 18, pp. 2952-2963, 2007.

[50] S. Barter, L. Molent, N. Goldsmith, and R. Jones, "An experimental evaluation of fatigue crack growth," Engineering Failure Analysis, vol. 12, no. 1, pp. 99-128, 2005.

[51] N. E. Frost and D. S. Dugdale, "The propagation of fatigue cracks in sheet specimens," Journal of the Mechanics and Physics of Solids, vol. 6, no. 2, pp. 92-110, 1958.

[52] J. R. Mohanty, B. B. Verma, and P. K. Ray, "Determination of fatigue crack growth rate from experimental data: a new approach," International Journal of Microstructure and Materials Properties, vol. 5, no. 1, pp. 79-87, 2010.

[53] M. Grasso, F. Penta, P. Pinto, and G. P. Pucillo, "A fourparameters model for fatigue crack growth data analysis," Frattura ed Integrita Strutturale, no. 26, pp. 69-79, 2013.

[54] N. J. Nagelkerke, "A note on a general definition of the coefficient of determination," Biometrika, vol. 78, no. 3, pp. 691692, 1991.

[55] Alcoa Mill Products, Alloy 2024 Sheet and Plate, Excellent Fatigue Properties-Consistent Performance, Alcoa Mill Products, Bettendorf, Iowa, USA, 1991, http://www.millproducts-alcoa.com. 
[56] J. C. Newman, X. R. Wu, M. H. Swain, W. Zhao, E. P. Phillips, and C. F. Ding, "Small-crack growth and fatigue life predictions for high-strength aluminum alloys. Part II: crack closure and fatigue analyses," Fatigue and Fracture of Engineering Materials and Structures, vol. 23, no. 1, pp. 59-72, 2000. 

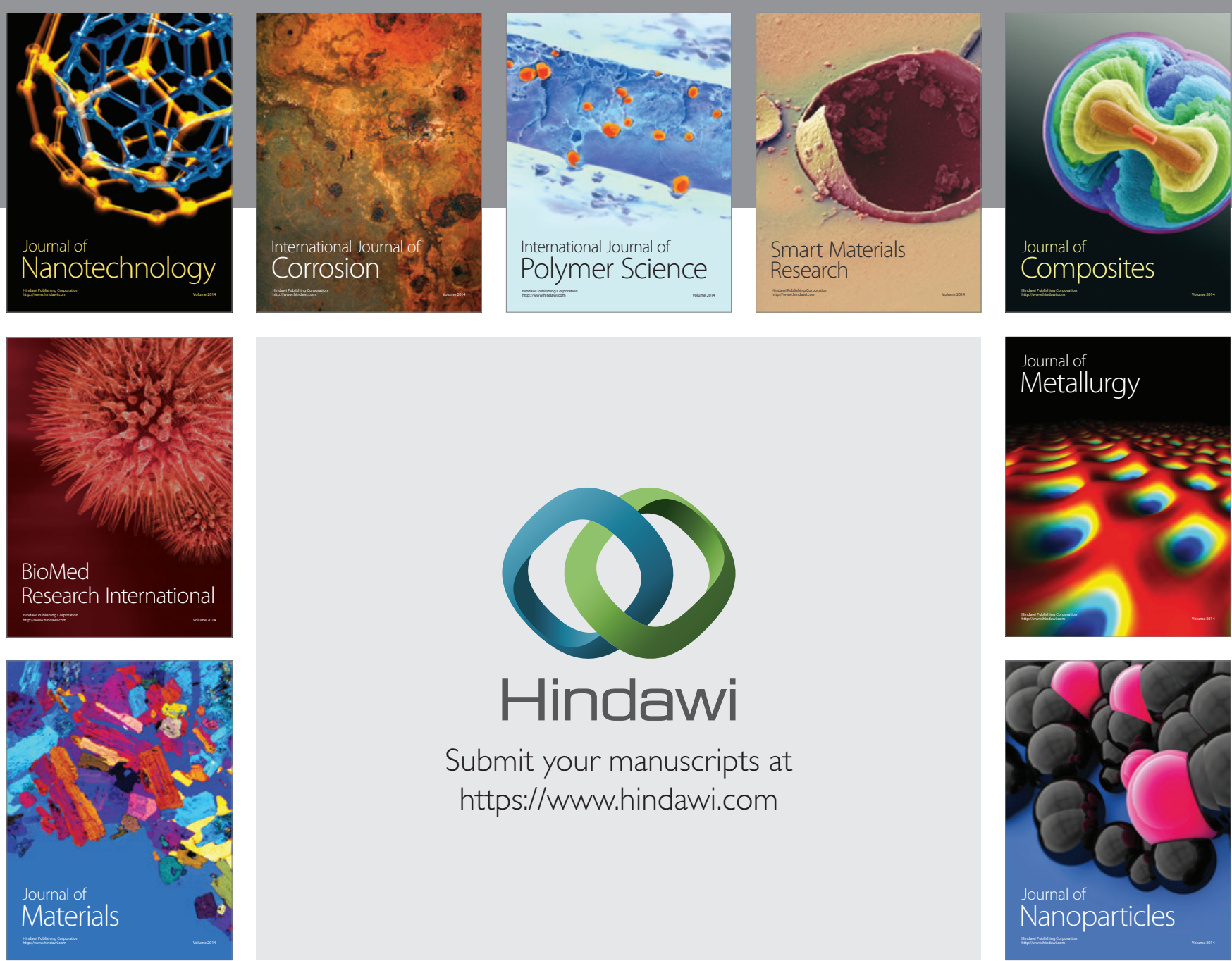

\section{Hindawi}

Submit your manuscripts at

https://www.hindawi.com

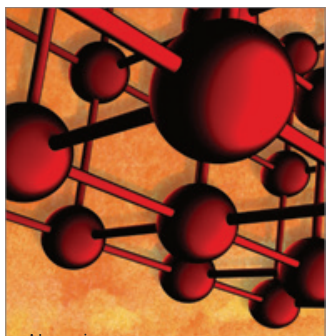

Materials Science and Engineering
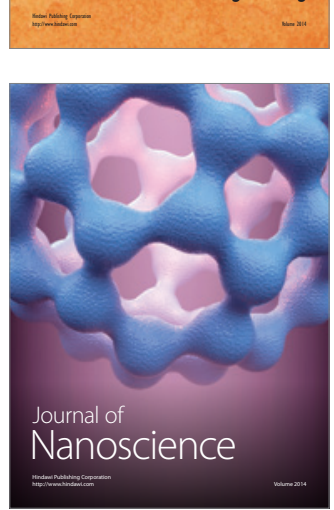
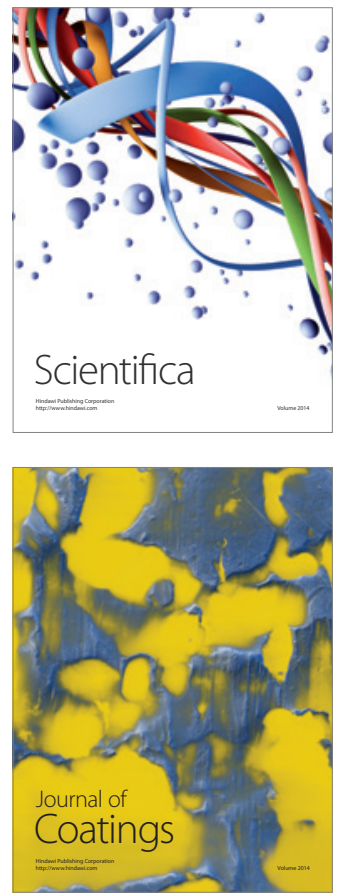
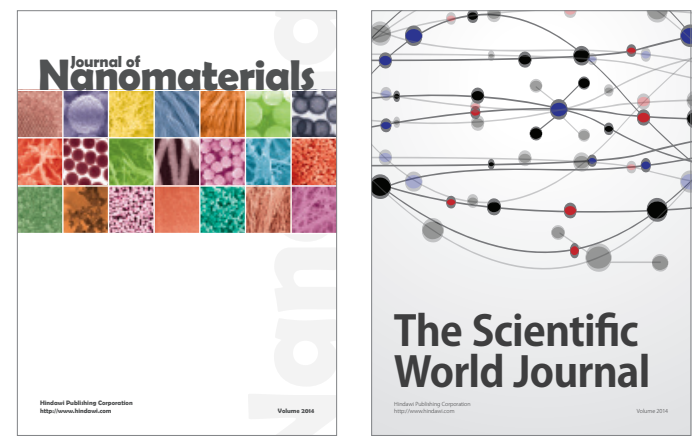

The Scientific World Journal
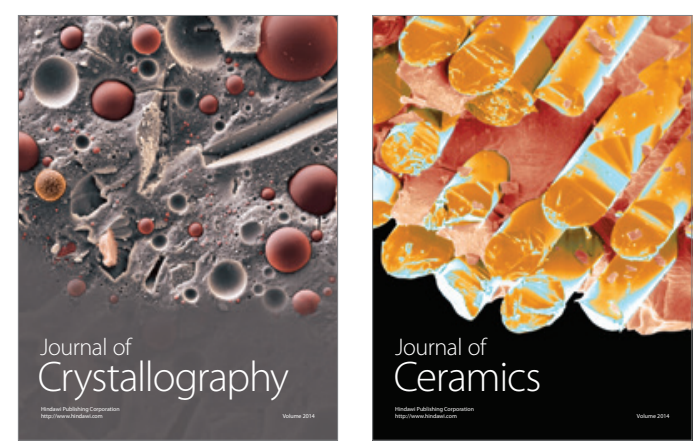
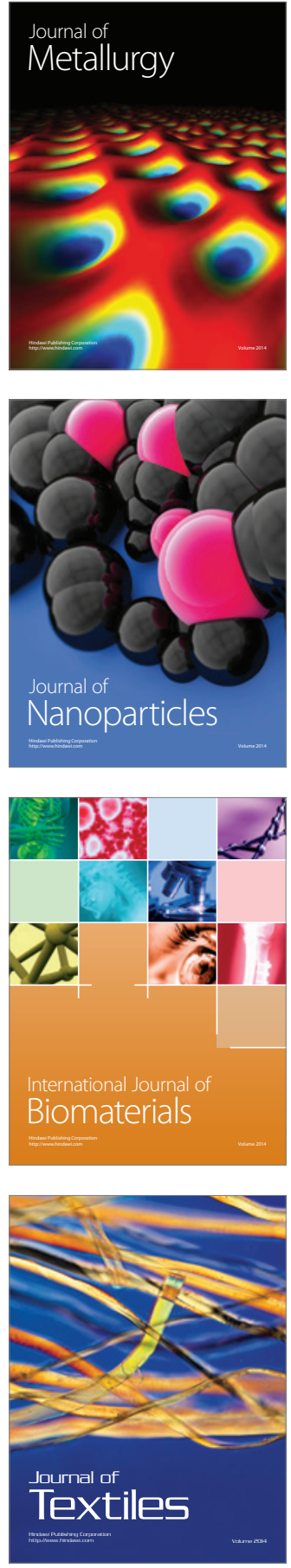